\title{
A EDUCAÇÃO AMBIENTAL E O ACESSO À INFORMAÇÃO SOBRE OS PRODUTOS AGRÍCOLAS ALIMENTARES
}

\author{
Katia Carolino ${ }^{1}$ \\ Rodrigo Machado ${ }^{2}$ \\ Marcos Sorrentino ${ }^{3}$
}

Resumo: O artigo apresenta breve revisão sobre o campo da Educação Ambiental (EA), destacando sua tendência crítica, e como a legislação aborda a informação sobre produtos agrícolas. Expõe a legislação que orienta comportamentos dos produtores como subsídio a uma EA crítica. Produção, consumo e suas regulações se tornam recursos pedagógicos vinculados ao dia-a-dia dos cidadãos. Utilizou-se levantamento bibliográfico e documental. Identificou-se rigidez na legislação para produtos agrícolas "orgânicos", mas não o mesmo rigor para produtos com agrotóxico. A aprovação de normas que exijam nos alimentos informações sobre agrotóxicos pode subsidiar a educação de cidadãos que cumprem o papel de consumidores em uma sociedade passível de reflexão crítica.

Palavras-chave: Legislação; Produto Orgânico; Produto com Agrotóxico e Afins; Educação Ambiental.

Abstract: The article presents a brief review on the field of Environmental Education (EA), highlighting its critical tendency and how the legislation addresses information about agricultural products. It exposes the legislation that guides the behavior of producers as a subsidy to a critical EA. Production, consumption and its regulations become pedagogical resources linked to the day-to-day of citizens. A bibliographical and documentary survey was used. Rigorous legislation was identified for "organic" agricultural products, but not the same rigor for products with pesticides. The adoption of standards requiring food information on pesticides can subsidize the education of citizens who play the role of consumers in a society that is susceptible of critical reflection.

Keywords: Legislation; Organic Product; Product with Pesticides and the Like; Environmental Education

\footnotetext{
1 Universidade de São Paulo. E-mail: kacarolino@usp.br.

2 Universidade de São Paulo. E-mail: rodrigomachado@usp.br

3 Universidade de São Paulo. E-mail: sorrentino.ea@gmail.com
} 


\section{Introdução}

O presente artigo tem como objetivo apresentar uma análise sobre a potencialidade de processos educadores que contribuem para promover a sensibilização para o consumo consciente com vistas a incentivar uma alimentação adequada, tomando isso como temário gerador de problematizações em perspectiva crítica ao modelo hegemônico de produção, distribuição e consumo.

Como subsidio à análise, o artigo também apresenta como a legislação federal brasileira regulamenta o direito de acesso à informação dos produtos agrícolas alimentares - orgânico ou com agrotóxico e afins - nos rótulos das embalagens ou nos recipientes de alimentos vendidos a granel ou in natura, com vistas a mostrar que a legislação, além de cumprir a sua função primordial de controle sobre os comportamentos e ações dos indivíduos (no caso, dos fornecedores de produtos agrícolas alimentares), também pode promover, como consequência, a sensibilização para o consumo consciente com vistas a incentivar uma alimentação adequada, sem riscos à saúde humana.

Para tanto, os processos de formulação de tais normas podem ser compreendidos como contexto e insumo de intervenções educadoras em perspectiva crítica e orientação socioambientalista. Já existem trabalhos de EA desenvolvidos nesse sentido, como se observa em Fassis (2014), Fassis e Carvalho (2015). Em relação aos produtores rurais, sobretudo familiares, é possível identificar pesquisas como a de Monteiro (2016).

Como finalidade de ambos os objetivos, o texto expressa o gesto de trazer ao debate no campo da EA a importância de articular diferentes disputas, como aquelas associadas à produção de alimentos (produção orgânica, agroecológica, agroflorestal versus agronegócio). Assim como dá destaque ao potencial da legislação para tornar-se um importante recurso pedagógico vinculado ao dia-a-dia de qualquer pessoa, podendo ser utilizado por educadores e educadoras ambientais, inclusive para problematizar os processos de formulação de normas que pretendem orientar e/ou controlar a produção, a distribuição e o consumo.

Esse debate é importante uma vez que, nas disputas associadas à produção de alimentos, há quem preconize o uso seguro dos agrotóxicos, ocultando uma série de benefícios recebidos pelas indústrias, especialmente no Brasil, que, por sua vez, se tornou o principal destino de produtos banidos no exterior devido à alta toxicidade. Em geral, se apresenta à opinião pública os sucessos que o setor agrícola brasileiro desempenha na economia brasileira, porém se esconde as agressões impingidas ao meio ambiente e à saúde humana. 
A título de exemplo, no início de 2019 o Ministério da Agricultura liberou o registro de 239 novos agrotóxicos ${ }^{4}$, sendo que alguns foram considerados extremamente tóxicos pela Agência Nacional de Vigilância Sanitária (ANVISA), números que só vem aumentando, conforme demonstram as agências de pesquisa. Neste contexto, o artigo destaca as potencialidades que o direito à informação associados a um processo educador podem produzir na sociedade de consumo de produtos agrícolas.

O acesso à informação é um direito que está previsto na Constituição Federal de 1988 e que foi regulamentado por diversas leis. No caso específico das relações de consumo, a Lei Federal no 8.078, de 11 de setembro de 1990, conhecida como Código de Defesa do Consumidor (CDC), regulamenta questões que se referem a produtos e serviços ofertados pelo fornecedor ao consumidor final. É um instrumento legal bastante completo no que se refere ao direito de acesso à informação ao consumidor em relação aos produtos e serviços colocados no mercado pelos fornecedores. No entanto, o texto legal não faz menção explícita sobre a necessidade de fazer a indicação nos rótulos das embalagens ou nos recipientes de alimentos vendidos a granel ou in natura se o produto é orgânico ou com agrotóxico e afins.

Sendo assim, este estudo observa a legislação como recurso significativo para o desenvolvimento de processos educadores em perspectiva crítica sobre a produção e consumo de alimentos em uma sociedade caracterizada pela desigualdade no tratamento dispensado à produção de commodities, de alimentos em escala industrial e à produção de alimentos livres de agrotóxicos, assim como àqueles processos de desenvolvimentos de normas que orientam, regulam e controlam tais relações sociais, incluindo o consumo.

Pretende, portanto, demonstrar a importância da legislação no que tange à promoção de uma maior transparência sobre a qualidade dos produtos agrícolas alimentícios - orgânicos ou com agrotóxicos e afins aos consumidores. O estudo também dá ênfase ao papel da legislação como expediente pedagógico voltado à sensibilização para o consumo consciente, visando incentivar uma alimentação adequada, sem riscos à saúde humana. Tomado como instrumento de ordenamento da vida coletiva, o processo de elaboração dessa legislação também serve de subsídio para promover a importância do engajamento político de cidadãos conscientes, seja pelas vias do consumo, da incidência política ou ambas.

Ainda que o uso de agrotóxicos na produção de alimentos agrícolas seja de conhecimento público, o assunto não é pautado no dia-a-dia do cidadão brasileiro, motivo pelo qual esta informação nos rótulos das embalagens ou nos recipientes de alimentos vendidos a granel ou in natura diretamente ao consumidor se torna necessária a uma sensibilização para o denominado

4 Fonte: https://g1.globo.com/jornal-nacional/noticia/2019/06/28/governo-acelera-liberacao-douso-de-novos-agrotoxicos-no-pais.ghtml. Acessado em: $11 \mathrm{Jul} .2019$ 
consumo consciente. Estudo com estudantes da educação básica de uma escola no Rio de Janeiro apresentado por Viana e Tatagiba-Araújo (2016), por exemplo, dão conta de que a palavra "doenças" foi a mais associada aos agrotóxicos e que os estudantes pesquisados identificavam riscos de intoxicação ou contaminação. Contudo, mais de $70 \%$ não sabiam que havia uma lei específica tratando do assunto. No caso, se referem à Lei Federal $n^{\circ}$ 7.802 , de 11 de julho de $1989^{5}$ e sua regulamentação - Decreto № 4.074, de 04 de janeiro de 2002.

A promoção de deslocamentos na compreensão, no comportamento e na postura política do cidadão consumidor é um processo que, por sua vez, exige ações de sensibilização, tomada de consciência e, também, engajamento político, mesmo quando no papel de consumidores. Para tanto, o acesso a informações adquire relevância. Essas informações podem ser provenientes de várias formas, seja pela mídia, redes sociais, mobilização social, ou até mesmo pela legislação, considerada por este estudo como um dos elementos-chave para sensibilização para o consumo consciente. No entanto, o desafio é como tornar esse conjunto de fontes de informação insumo de processos educadores socioambientalmente orientados e politicamente estimulantes, uma vez que, difusas, desagregadas, individualizadas, descontextualizadas e não refletidas, correm o risco de perderem-se ou terem reduzido seu potencial formativo.

\section{Procedimentos}

Com relação à intenção de expor como os processos educadores podem contribuir para promover a sensibilização para o consumo consciente, com vistas a incentivar uma alimentação adequada, este breve estudo recorreu ao campo da EA em fontes bibliográficas, observando as tendências identificadas e suas orientações de ordem filosófica, epistemológica e metodológica, de forma a balizar a análise e fundamentar um posicionamento necessário ao referido objetivo.

Em relação à legislação sobre o acesso a informação, o estudo foi produzido a partir de pesquisa bibliográfica realizada nos principais bancos de dados acadêmicos e também por pesquisa documental no site do Ministério da Agricultura, Pecuária e Abastecimento, no que se refere à legislação sobre produtos agrícolas orgânicos, e no site da Câmara dos Deputados, no que se refere à legislação sobre agrotóxicos e afins.

\footnotetext{
${ }^{5}$ Dispõe sobre a Pesquisa, a Experimentação, a Produção, a Embalagem e Rotulagem, 0 Transporte, o Armazenamento, a Comercialização, a Propaganda Comercial, a Utilização, a Importação, a Exportação, o Destino Final dos Resíduos e Embalagens, o Registro, a Classificação, o Controle, a Inspeção e a Fiscalização de Agrotóxicos, seus Componentes e Afins, e dá outras Providências.
} 


\section{Resultados}

Com vistas a atingir os objetivos enunciados na Introdução, este item foi dividido em duas partes. Na primeira parte, o artigo apresenta o debate em EA do qual emergem tendências, perspectivas e abordagens da EA. Em seguida, traz os principais fundamentos da EA crítica - perspectiva adotada no artigo por ser o mais pertinente para embasar a discussão em tela relacionada ao modelo hegemônico de produção, distribuição e consumo.

Feitas tais considerações, o texto apresenta os resultados da pesquisa realizada na legislação federal que trata da normatização sobre o acesso à informação em relação ao que contém ou não agrotóxico, inclusive projetos de lei em tramitação sobre o assunto, mostrando a contradição em relação as exigências legais que são feitas para os produtos que não contém agrotóxicos e a ausência de legislação em relação aos produtos que contém agrotóxicos e afins.

\section{Educação Ambiental: tendências, perspectivas e abordagens}

\section{Macrotendências da EA}

A EA tem sido compreendida a partir da noção de campo social, trabalhada pelo sociólogo francês Pierre Bourdieu. Tal noção entende o campo como um espaço social no qual diferentes agentes sociais atuam tanto na dimensão da prática quanto do discurso. Por se caracterizar como um espaço plural, com diferentes agentes, produzindo diversos discursos e práticas, observa-se no campo social também disputas simbólicas e materiais. Disputa por hegemonia, sobre o que predomina em se tratando de como se pensa determinado "objeto" de atenção e dedicação que atrai esses diferentes agentes, assim como se atua em relação ao mesmo.

O campo compreende, segundo Layrargues e Lima (2014, p.23), apoiando-se na obra de Bourdieu, "[...] um conjunto de relações de dominação, subordinação e adesão associado a estratégias ideológicas de conservação ou de subversão da ordem estabelecida dentro deste espaço social".

[...] o campo da EA é composto por uma pluralidade diversificada de indivíduos ou grupos sociais que dividem, enquanto membros de um campo, um núcleo de valores, de normas e de características comuns, embora também tenham outras características que os diferenciam entre si, que têm concepções diferenciadas sobre a questão ambiental e que defendem propostas pedagógicas diversas para abordar essa questão, algumas das quais se identificam primordialmente com a estabilidade e conservação das relações sociais e das relações entre a sociedade e o ambiente e outras que defendem a transformação dessas mesmas relações. Além disso, as diferenças entre as concepções e os projetos de sociedade se refletem, naturalmente, sobre as práticas

educativas efetivamente desenvolvidas e, todas essas


diferenças internas ao campo quanto às características dos sujeitos, às concepções que esses sujeitos têm da realidade e às ações que eles protagonizam na vida social disputam entre si a hegemonia do campo da EA e a possibilidade de orientá-lo de acordo com sua interpretação e seus interesses (LIMA, 2005, p.85).

Em obras anteriores à tese de Lima, Guimarães $(2000,2004)$ questiona um suposto consenso em torno do que seria e qual o sentido da EA. Ao perguntar se o consenso ocultaria na realidade um embate, Guimarães sugere em seus trabalhos duas grandes correntes na forma de conceber EA. Ao buscar organizar um conjunto de argumentos, justificativas, preocupações e práticas de uma EA denominada "crítica", o autor anuncia a corrente tomada como "conservadora".

Um dos argumentos de Guimarães (2004) reside na percepção de que estaria se consolidando uma perspectiva de EA que se coaduna com uma compreensão sobre educação, práticas pedagógicas e concepção de mundo alinhadas ideologicamente com a manutenção e reprodução da sociedade atual.

Diante de quadro semelhante, Carvalho (2004) trabalha a tese de se fortalecer a demarcação de uma EA crítica. Defendendo o acréscimo do adjetivo "crítica" à EA, a autora afirma que apenas o adjetivo "ambiental" não é suficiente para definir determinada postura ético-política. Justamente para "[...] situar o ambiente conceitual e político onde a educação ambiental pode buscar sua fundamentação enquanto projeto educativo que pretende transformar a sociedade" (CARVALHO, 2004, p.18).

E a partir dessa perspectiva crítica, há, no Brasil, outras adjetivações à EA. Ecopedagogia ou Pedagogia da Terra (GADOTTI, 2001), EA Transformadora (LOUREIRO, 2006), EA emancipatória (LIMA, 2004). Ainda antes, Sorrentino (1995 e 2002) já teria buscado, no âmbito brasileiro, organizar as diferentes identidades e correntes observadas pelo autor - EA ao ar livre, EA e economia ecológica, EA conservacionista e EA na gestão ambiental. Desde ali, Sorrentino anunciava, com base em sua análise do período entre os encontros em Tbilisi (1977) e Thessaloniki, Grécia (1997), a premência de uma EA voltada à incidência em políticas públicas, como a educacional e a ambiental.

Layrargues e Lima (2014) concluem que nesse campo social da EA, no Brasil, há três macrotendências. A análise que fazem do campo da EA apresenta uma associada a um movimento conservacionista; uma segunda a posturas pragmáticas e a terceira com perspectiva crítica acentuada, caracterizando sua orientação e atuação política. Essa terceira macrotendência, que se destaca neste artigo, "apoia-se com ênfase na revisão crítica dos fundamentos que proporcionam a dominação do ser humano e dos mecanismos de acumulação do capital, buscando o enfrentamento político das 
desigualdades e da injustiça socioambiental' (LAYRARGUES, LIMA, 2014, p.33).

\section{EA Crítica: fundamentos}

Nessa tendência que adjetiva a EA como crítica, se busca promover o estranhamento das relações sociais localizando-as na estrutura de problemas, então, socioambientais. Nela há valores, identidades, reflexões e práticas correspondentes entre si que, por partirem da perspectiva crítica em termos de análise da sociedade e de sua relação com o meio ambiente, apontariam para transformações sociais e teriam em seu horizonte a superação do padrão de relações sociais de produção hegemônico.

Essa formação em perspectiva crítica, segundo Tozoni-Reis (2007), Trein (2007) toma como referencial o pensamento marxiano. Remetendo-se tanto à Teoria Crítica como também aos estudos do pesquisador francês em Educação e Pedagogia, Henry Giroux, Tozoni-Reis (2007) rememora a origem do termo "pedagogia crítica" e o expande em termos de referencial, propondo-se a pensá-lo de forma ampliada, a partir de um referencial comum às "teorias críticas": o pensamento marxista. Mais adiante, em sua reflexão sobre as contribuições possíveis a uma pedagogia crítica, Tozoni-Reis afirma:

[...] podemos considerar que a educação ambiental como dimensão da educação é atividade intencional da prática social que imprime ao desenvolvimento individual um caráter social em sua relação com a natureza e com os outros seres humanos, com o objetivo de potencializar essa atividade humana, tornando-a mais plena de prática social e de ética ambiental (TOZONI-REIS, 2007, p.218).

A autora resgata a concepção de EA construída por diferentes participações no Fórum Internacional das ONG, em 1992, e registrada no Tratado de EA para Sociedades Sustentáveis e Responsabilidade Global. Para a autora, a EA voltada à sustentabilidade, nesse documento, "[...] é uma educação política, na perspectiva democrática, libertadora e transformadora" (TOZONI-REIS, 2007, p.177). Ao substituir a expressão "desenvolvimento sustentável" - no singular - por "sociedades sustentáveis" - com destaque ao plural - tal compreensão de EA e atribuição de sentidos à mesma configuraria, por si, deslocamentos substantivos de concepções (sobre desenvolvimento e sustentabilidade), produzindo implicações teóricas e políticas profundas.

Ainda quanto ao Tratado, para Raymundo, Branco e Biasoli (2018, p.338), sua grande marca 
[...] estava no fato de colocar a criticidade e os respectivos processos sócio-históricos de constituição da crise ambiental e civilizatória, em oposição à educação ambiental conservacionista, que não apresentava noções políticas e críticas atreladas às desigualdades sociais e ambientais.

Pedrosa (2007), além da contribuição marxiana, aponta mais especificamente a Teoria Crítica, vinculada às reflexões e formulações desenvolvidas no âmbito da Escola de Frankfurt. Algumas das razões para se tomar tais reflexões localizam-se em suas características de analisar os processos de legitimação do Estado na sociedade de consumo, a crítica ao uso ideológico da ciência e da tecnologia, a problematização da construção das subjetividades contemporâneas vinculadas a necessidades materiais e simbólicas subsumidas à lógica individualista, competitiva e consumista e à crítica da hegemonia da racionalidade instrumental em detrimento da razão emancipatória.

Uma questão que emerge desse debate que mobiliza repertórios distintos, mas associados, como o são a problemática ambiental e a crítica à economia política, conforme apontam Foladori (1999) e Foster (2012), demanda reflexões, de ambas as partes - ambientalismo e esquerda marxista. Reflexões que busquem atualizar o segundo no que se refere às limitações físicas apresentadas pelo planeta, assim como fundamentar com contribuições da crítica à economia política o questionamento ambientalista a um modelo de desenvolvimento hegemônico e apoiado na ficção do desenvolvimento ad aeternum das forças produtivas e do crescimento econômico infinitos.

\section{Tentativas de normatizar o acesso à informação sobre o que contém ou não agrotóxicos}

A legislação federal brasileira estabelece a obrigatoriedade de informar ao consumidor final que o produto é orgânico. Para tanto, é necessário que 0 produto esteja certificado por um dos três mecanismos descritos a seguir: 1) certificação por auditoria; 2) sistema participativo de garantia; e 3) controle social na venda direta sem certificação.

O SisOrg (Sistema Brasileiro de Avaliação da Conformidade Orgânica) é uma estrutura governamental que concede o selo de produto orgânico que, por sua vez, garante ao consumidor que o produto atende a uma série de princípios adotados em todas as fases de produção. Assim, para os produtores que desejam vender seus produtos em mercados, supermercados ou lojas, a legislação exige que os rótulos das embalagens contenham o selo federal do SisOrg, conforme modelo que segue abaixo, mesmo que sejam produtos estrangeiros. 


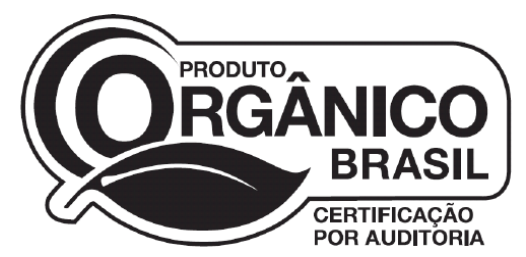

Figura 1: Selo do SisOrg.

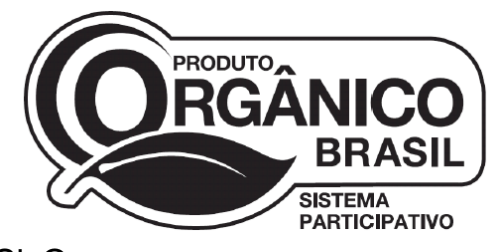

Fonte: Instrução Normativa ํำ 18, de 20 de junho de 2014.

No caso dos produtos sem certificação, provenientes do Controle Social na Venda Direta, a legislação exige que o produtor apresente um documento chamado Declaração de Cadastro. Nesse caso, só o produtor ou alguém de sua família ou de seu grupo de agricultores poderá fazer a venda direta ao consumidor. Portanto, os produtores não podem vender para terceiros, como mercados, supermercados ou lojas, apenas nas feiras ou direto para os consumidores e/ou compras governamentais.

Em relação aos produtos vendidos a granel, o fornecer é obrigado a identificar corretamente que o produto é orgânico em cartazes, etiquetas ou qualquer outro meio. No caso de restaurantes, lanchonetes e hotéis que servem alimentos com ingredientes orgânicos, a lei estabelece que devem ser mantidas à disposição dos consumidores listas dos ingredientes orgânicos, bem como dos fornecedores dos ingredientes.

Com relação aos produtos agrícolas alimentares que contêm agrotóxicos e afins, foram identificados três projetos de lei em nível federal. A primeira proposta - projeto de lei no 6.448, apresentado em 18 de novembro de 2009 propõe acrescentar o dispositivo 11-A ao CDC para estabelecer que "na comercialização dos produtos alimentares destinados ao consumo humano ou animal, devem constar informações no rótulo sobre os agrotóxicos e afins utilizados na produção agropecuária dos ingredientes, bem como, na forma do regulamento, sobre os medicamentos empregados na produção animal". Acrescenta ainda um parágrafo que determina que "as informações previstas no caput devem constar no rótulo dos produtos alimentares embalados na ausência do consumidor e nos recipientes de alimentos vendidos a granel ou in natura diretamente ao consumidor, bem como nos respectivos documentos fiscais".

A segunda proposta - projeto de lei $\mathrm{n}$ ํ1.297, apresentado em 28 de abril de 2015, propõe que os rótulos e as embalagens de todos os produtos não orgânicos comercializados para o consumo humano contenham a frase de advertência "Produzido com Agrotóxico" impressa, bem como a origem do alimento e o tipo de pesticida utilizado e os possíveis malefícios à saúde do consumidor. Com relação aos produtos orgânicos propõe que as embalagens e rótulos contenham a expressão: "Livre de Agrotóxico", bem como sua origem, data de produção e validade. Nos casos em que o fornecedor comercializar fora das embalagens e rótulos, as informações sobre os produtos orgânicos e 
não orgânicos deverão constar junto ao material divulgação que contiver o preço e a especificação do produto.

Por fim, a terceira proposta - oㅜ 10.082, apresentado em 19 de abril de 2018, propõe a aprovação de uma lei que tratado direito a informação sobre o uso de agrotóxicos em alimentos. Para tanto, propõe, dentre outras coisas, que "os fornecedores deverão informar nas embalagens dos alimentos, de forma clara e adequada, os agrotóxicos utilizados no seu cultivo" (artigo $2^{\circ}$ ) e que "as informações sobre os agrotóxicos utilizados no cultivo de produtos in natura deverão estar em local visível próximo ao de exposição dos alimentos" (artigo $2^{\circ}$, parágrafo único).

\section{Discussão}

Em linhas gerais, a legislação estabelece uma série de regras específicas para a rotulagem de alimentos, inclusive impõe a obrigatoriedade de uma rotulagem nutricional dos alimentos sob a justificativa de que o consumidor poderá decidir e optar por alimentos que não comprometam sua saúde (TEIXEIRA, 2017). No entanto, informações sobre os agrotóxicos são negligenciadas aos consumidores.

Existe uma rígida legislação que exige que o fornecedor identifique um produto agrícola como "orgânico" para que o consumidor final tenha o direito de acesso à informação e o de escolha em relação ao produto que irá consumir. Essa legislação torna as relações de consumo mais transparentes, inclusive, por exigir um selo oficial (padronizado) nos rótulos das embalagens dos produtos, bem como a identificação "orgânico" nos casos de venda a granel ou in natura, com exceção dos produtos que, sem certificação, podem ser vendidos diretamente para o consumidor final, portanto sem intermediários. Neste último caso, o produtor é obrigado a ter uma Declaração de Cadastro.

Contudo, não existe o mesmo rigor na legislação para informar ao consumidor que determinado produto foi produzido com o uso de agrotóxicos e afins. Para Ferreira (2013), que defendeu a tese de doutorado intitulada " $A$ regulação do uso dos agrotóxicos no Brasil: uma proposta para um direito de sustentabilidade", os produtos com agrotóxicos deveriam ser obrigados a estampar imagens acerca dos malefícios que causam à saúde, principalmente nos casos em que a toxidade for extremamente elevada. Enquanto que para Hupfferm e Pol (2017), no artigo intitulado "o direito de escolha do consumidor e a necessária informação sobre alimentos com agrotóxicos", o uso, o tipo e a quantidade de agrotóxicos, percentual de resíduo remanescente no alimento e potenciais riscos à saúde e ao meio ambiente precisam estar inseridos nos rótulos dos alimentos.

Isto é necessário, pois ainda que o uso de agrotóxicos na produção de alimentos seja bastante divulgado, o assunto não é abordado no dia-a-dia do cidadão brasileiro. Sem contar que inverteria a lógica na qual se observa atualmente de que aqueles que produzem alimentos saudáveis têm o dever informar. Ao invés disso, seriam os produtos nocivos à saúde que teriam a

revista brasileira educação ambiental 
obrigação de conter advertências aos cidadãos sobre os riscos de consumir alimentos com agrotóxicos.

Sendo assim, não se nega que o direito a informação é considerado um elemento importante para subsidiar intenções pedagógicas direcionadas a cidadãos que cotidianamente assumem o papel de consumidores. No entanto, a mudança de comportamento e de postura política do cidadão consumidor é um processo que requer mais do que o acesso à informação. Demanda trabalho educativo em perspectiva crítica entendendo tais informações como subsídios substantivos.

Essa afirmação pode ser confirmada pelos estudos realizados por Galindo e Portilho (2015) sobre como os consumidores entendem os riscos dos agrotóxicos e dos transgênicos na alimentação. Segundo as autoras, as pessoas já tem alguma familiaridade ou já ouviram falar dos riscos associados ao consumo de produtos com agrotóxicos ou transgênicos, mesmo assim não integraram, de maneira determinante, às suas preocupações, seja em casa ou na sociedade, nem mesmo em seus hábitos cotidianos de consumo alimentar, confirmando que apenas a informação sobre agrotóxicos e seus efeitos nocivos não são suficientes para mudar hábitos de consumo de alimentos, muito menos promover uma mudança de paradigma.

Segundo informações do Ministério do Meio Ambiente ${ }^{6}$, o Brasil é o maior consumidor de agrotóxicos no mundo, motivo que reforça a necessidade de processos educadores, com objetiva intencionalidade pedagógica, não apenas para a conscientização sobre a periculosidade dos riscos no uso destes produtos químicos na produção agrícola, mas também para promover ações coletivas que tenha por finalidade incidir em políticas públicas e, consequentemente, na mudança da legislação, reconhecendo quais instrumentos nosso modelo de sociedade dispõe e como utilizá-los politicamente.

Embora os cidadãos consumidores sejam a parte mais vulnerável nas relações de consumo, há relativo poder no que diz respeito à consciência e posicionamento político que orientam suas escolhas e posturas sobre os produtos agrícolas alimentares colocados à disposição no mercado de consumo. E, embora esse poder pressuponha um cidadão consumidor consciente e sensibilizado para uma causa pública, é necessário reconhecer o risco da individualização dessa sensibilização e conscientização corresponder a uma espécie de atomização do ponto de vista político, ou seja, um isolamento no indivíduo que não transcenda 0 ato de consumir. Portanto, prescindindo da troca, do contato, do debate e da organização coletiva alinhada a um projeto societário que tenha como premissa transformações no modelo de produção, distribuição e consumo de forma geral, não apenas de produtos agrícolas.

6 Fonte: http://www.mma.gov.br/seguranca-quimica/agrotoxicos. Acessado em 31 de maio de 2018. 
Neste contexto, considerando-se a breve exposição sobre o campo da EA crítica exposto anteriormente e a ênfase dada à $E A$, o artigo destaca alguns aspectos / possibilidades acerca de como a EA pode contribuir para mudanças nesse cenário aqui tomado como importantes:

Primeiro, reconhecer as sérias limitações de restringirem-se a expectativas de mudanças de comportamento individual, afastando-se da compreensão de que as circunstâncias materiais em que vivem as pessoas condicionam fortemente suas ações em qualquer plano. Segundo, não circunscrever eventuais beneficiários desses processos educadores à condição de consumidores. São, antes, cidadãos, com direitos constitucionais à informação, ao meio ambiente equilibrado, à saúde e a uma alimentação adequada. Terceiro, as questões da produção, da distribuição e do consumo se enquadram em determinado contexto histórico, social, político, econômico e cultural (incluindo-se sua expressão legal e normativa), de maneira que processos de EA alinhados com a perspectiva crítica devem atentar à devida contextualização do "objeto" com que trabalha, seja a produção de alimentos e as regras de informação a seu respeito, tratadas neste artigo, seja qualquer outro que sirva como tema gerador ou recurso pedagógico.

A esse debate sobre a EA contribuir não somente com eventuais mudanças de comportamento de cidadãos consumidores, mas também ao comportamento político das pessoas pode ser observada a partir de reflexão trazida pelo uruguaio Eduardo Gudynas, pesquisador do Centro Latinoamericano de Ecologia Social (CLAES). Em artigo sobre cidadania ambiental, o autor traz um alerta sobre diferentes reivindicações políticas para a denominada "cidadania ambiental".

De um lado, um projeto societário neoliberal demanda indivíduos exercendo sua cidadania individualmente (GUDYNAS, 2009), como se a soma de ações conscientes em um mercado livre fosse suficiente para transformar situações indesejadas. Por outro lado, e corroborando posicionamento fundamentado de Dagnino (2004), um projeto societário de aprofundamento da democracia reconhece a insuficiência de ações isoladas, demandando, portanto, ações politicamente articuladas entre sujeitos coletivos conscientes e construtores de uma transição para sociedades sustentáveis. Transição que supere a realidade contextualizada, problematizada e apreendida nos referidos processos educadores com orientação socioambientalista (inclusive tendo a incidência na legislação e em políticas públicas como estratégias políticas).

Diante do exposto, processos educadores ambientalistas, com explícita intencionalidade pedagógica, são fundamentais para promover ações mais desafiadoras que incluam perspectivas críticas acerca do modelo de desenvolvimento hegemônico e mudança de paradigma para sociedades sustentáveis. 


\section{Considerações finais}

Observou-se que a legislação não impõe aos fornecedores de produtos agrícolas alimentares que utilizam agrotóxico a necessidade de informar, seja nas embalagens ou em qualquer outro local adequado, que o produto contém agrotóxico e afins. Nesse contexto, é fundamental a aprovação de projetos de lei como os que se encontram em tramitação na Câmara dos Deputados para que os cidadãos possam ter o direito de acesso à informação sobre os produtos que consomem diariamente, não apenas para os produtos orgânicos.

Para tanto, a contribuição da EA a um cenário como esse, considerando o debate exposto neste artigo e a opção filosófica e política pela tendência caracterizada como crítica, apoia-se no reconhecimento dos aspectos destacados, a fim de não individualizar cada cidadão consumidor como sujeito bem informado, porém isolado em uma disputa política ampla entre projetos de sociedade distintos e antagônicos. Para caracterizar-se como processo educador com compromisso crítico, emancipatório e transformador é preciso criar condições para se reconhecer e compreender os interesses e disputas em jogo, as relações com a qualidade ambiental e suas próprias condições de vida, além de tomar ciência de estratégias de incidência em legislações e políticas públicas como instrumentos de intervenção consciente. Isso, para além de mudanças comportamentais restritas a hábitos de consumidor.

No caso da legislação a respeito de informações sobre as condições de produção de alimentos (com agrotóxicos ou orgânicos), trazidos por este artigo, observou-se que sua relevância reside na possibilidade de configurar-se com um tema gerador significativo por sua proximidade ao cotidiano e condições de vida de qualquer pessoa, sobretudo em centros urbanos. Isso possibilita uma discussão acessível e de descomplicada adesão, sendo, portanto, de interesse público. Parte-se de questões imediatas e associadas à qualidade de vida, mesmo individual, das pessoas e caminha-se na direção, mais complexa e coletiva, das implicações econômicas, sociais e ambientais do uso de agrotóxicos na produção de alimentos.

Devidamente contextualizado, o tema da produção de consumo de alimentos com agrotóxicos ou orgânicos potencializa, inclusive, a reciprocidade nas relações entre consciência crítica, cidadania ambiental e a legislação e outras políticas públicas que ordenam a produção e o consumo de alimentos. Ou seja, formação de massa crítica que pressione para que haja legislação que obrigue o produtor a informar sobre o uso de agrotóxicos e suas consequências à saúde e ao meio ambiente, ao passo que a mesma legislação materialize tal consciência crítica no ordenamento da vida coletiva. 


\section{Referências}

CARVALHO, I.C.M. Educação Ambiental Crítica: nomes e endereçamentos da educação. In: LAYRARGUES, P.P. (org.). Identidades da Educação Ambiental Brasileira. Brasília, MMA, 2004.

DAGNINO, E. ¿Sociedade civil, participação e cidadania: de que estamos falando? In: MATO, D. (coord.). Políticas de ciudadanía y sociedad civil entiempos de globalización. Caracas: FACES, Universidad Central de Venezuela, 2004. p. 95-110.

FASSIS, F. Educação Ambiental e o uso de agrotóxicos. Dissertação. 215 fls. (Mestrado em Educação). Instituto de Biociências da Universidade Estadual Paulista Júlio de Mesquita. Rio Claro, 2014. Disponível em: https://repositorio.unesp.br/handle/11449/128049. Acessado em: 19 mai 2019.

FASSIS, F.; CARVALHO, L.M. Educação Ambiental e o uso de agrotóxicos: relações entre o modelo de produção agrícola, a exigência do conhecimento e o papel da escola. Comunicações. Ano 22, n. 2, p. 309-334. Ed. Especial. Piracicaba, 2015.

FERREIRA, M.L.P.C. A regulação do uso dos agrotóxicos no Brasil: Uma proposta para um direito de sustentabilidade. Tese. $346 \mathrm{fls}$. (Doutorado em Direito). Centro de Ciências Jurídicas. Universidade Federal de Santa Catarina Florianópolis. $\quad$ Florianopólis, 2013. Disponível em: https://repositorio.ufsc.br/xmlui/handle/123456789/122689. Acessado em: 19 mai 2019.

FOLADORI, G. O Capitalismo e a crise ambiental. Raízes. Ano XVIII, № 19, maio, 1999. Disponível em: http://outubrorevista.com.br/o-capitalismo-e-a-criseambiental/. Acessado em: 19 mai 2019.

FOSTER, J.B. A ecologia da economia política marxista. Lutas Sociais. São Paulo, n.28, p.87-104. 2012. Disponível em: https://revistas.pucsp.br/index.php/ls/article/view/18539. Acessado em: 19 mai 2019.

GADOTTI, M. Pedagogia da terra: Ecopedagogia e educação sustentável. In: TORRES, C.A. Paulo Freire y la agenda de la educación latino americana en el siglo XXI. Buenos Aires, CLACSO, 2001.

GALINDO, F.; PORTILHO, F. O Peixe Morre pela Boca: como os consumidores entendem os riscos dos agrotóxicos e dos transgênicos na alimentação. Sustentabilidade em Debate, Brasília, v. 6, n. 2, p. 77, maio/ago 2015. Disponível em: http://periodicos.unb.br/ojs248/index.php/sust/article/view/15505. Acessado em: 19 mai 2019.

GUDYNAS, E. Ciudadania ambiental y meta-ciudadanias ecológicas: revision y alternativas en America Latina. Desenvolvimento e Meio Ambiente, n. 19, p. 53-72, jan./jun. 2009. 
GUIMARÃES, M. Educação Ambiental Crítica. In: LAYRARGUES, P.P. (org.). Identidades da Educação Ambiental Brasileira. Brasília, MMA, 2004.

GUIMARÃES, M. Educação Ambiental: no consenso um embate? Campinas, Papirus, 2000.

HUPFFERM, H.M.; POL, J.J. O direito de escolha do consumidor e a necessária informação sobre alimentos com agrotóxicos. Revista do Programa de Pós-Graduação em Direito da UFC, v. 37, ํo 2, 2017. Disponível em: http://www.periodicos.ufc.br/nomos/article/view/5509. Acessado em: 19 mai 2019.

LAYRARGUES, P.P.; LIMA, G.F.C. As macrotendências político-pedagógicas da Educação Ambiental Brasileira. Ambiente \& Sociedade, São Paulo v. XVII, n. 1, p. 23-40, jan.-mar. 2014.

LIMA, G.C.F. Formação e dinâmica do campo da Educação Ambiental no Brasil: emergência, identidades, desafios. Tese (doutorado em Ciências Sociais). $207 \mathrm{fl}$. Instituto de Filosofia e Ciências Humanas. Universidade Estadual de Campinas. Campinas: Unicamp, 2005. Disponível em: http://repositorio.unicamp.br/jspui/handle/REPOSIP/279827. Acessado em: 19 mai 2019.

LOUREIRO, C.B.F. Movimento Ambientalista e o Pensamento Crítico: uma abordagem política. $2^{\mathrm{a}}$ ed. Rio de Janeiro: Quartet, 2006.

MONTEIRO, P.A.M. A perspectiva crítica da educação ambiental no combate ao risco pelo uso de agrotóxicos na lavoura da comunidade de Joanápolis, Goiás. Trabalho de Conclusão de Curso. 74 fls. (Licenciatura em Química). Instituto Federal de Educação, Ciência e Tecnologia de Goiás. Anápolis, 2016.

PEDROSA, J.G. O capital e a natureza no pensamento crítico. In: LOUREIRO, C.F.B. A questão ambiental no pensamento crítico: natureza, trabalho e educação. Rio de Janeiro, Quartet, 2007.

TOZONI-REIS, Contribuições para uma pedagogia crítica na educação ambiental: reflexões teóricas. In: LOUREIRO, C.F.B. A questão ambiental no pensamento crítico: natureza, trabalho e educação. Rio de Janeiro, Quartet, 2007.

RAYMUNDO, M.H.A.; BRANCO, E.; BIASOLI, S. Indicadores de Políticas Públicas de Educação Ambiental: Construção à Luz do Tratado de Educação Ambiental para Sociedades Sustentáveis e Responsabilidade Global e da Política Nacional de Educação Ambiental. Cadernos de Pesquisa: Pensamento Educacional, Curitiba, Número Especial, p.337-358 2018. Disponível em: https://seer.utp.br/index.php/a/article/view/1209/1040. Acessado em: 19 mai 2019.

SORRENTINO, M. Educação Ambiental e Universidade. (Tese). (Doutorado em Educação). Faculdade de Educação da Universidade de São Paulo. São Paulo, 1995. 
SORRENTINO, M. Crise ambiental e educação. In: QUINTAS, J.S. (Org.) Pensando e praticando a educação ambiental no Brasil. Brasília: IBAMA, $2002 b$

TEIXEIRA, T.M. Saúde e direito à informação: o problema dos agrotóxicos nos alimentos. Revista de Direito Sanitário, v. 17, no 3, nov. 2016/fev., São Paulo, 2017. Disponível em: http://www.revistas.usp.br/rdisan/article/view/127782. Acessado em: 19 mai 2019.

TOZONI-REIS, Contribuições para uma pedagogia crítica na educação ambiental: reflexões teóricas. In: LOUREIRO, C.F.B. A questão ambiental no pensamento crítico: natureza, trabalho e educação. Rio de Janeiro, Quartet, 2007.

TREIN, E. A contribuição do pensamento marxista à educação ambiental. In: LOUREIRO, C.F.B. A questão ambiental no pensamento crítico: natureza, trabalho e educação. Rio de Janeiro, Quartet, 2007.

VIANA, E.S.; TATAGIBA-ARAÚJO, G. Agrotóxicos e Educação Ambiental: Formando multiplicadores a favor da minimização dos riscos ao ambiente e à saúde. Disponível em: $<$ http://bd.centro.iff.edu.br/xmlui/bitstream/handle/123456789/942/ArtigoTCC IF F 2016.pdf?sequence=1\&isAllowed $=y$ >. Acessado em: 19 mai 2019.

\section{Sites Consultados:}

Fonte:

http://www.agricultura.gov.br/assuntos/sustentabilidade/organicos/regularizacao -da-producao. Acessado em 21 de junho de 2018.

Fonte: http://www.mma.gov.br/seguranca-quimica/agrotoxicos. Acessado em 31 de maio de 2018.

Fonte: https://g1.globo.com/jornal-nacional/noticia/2019/06/28/governo-aceleraliberacao-do-uso-de-novos-agrotoxicos-no-pais.ghtml.

Acessado em: 11 Jul. 2019 